\title{
A QFD-Based Mathematical Model for New Product Development Considering the Target Market Segment
}

\author{
Liang-Hsuan Chen and Cheng-Nien Chen \\ Department of Industrial and Information Management, National Cheng Kung University, Tainan 70101, Taiwan \\ Correspondence should be addressed to Liang-Hsuan Chen; lhchen@mail.ncku.edu.tw
}

Received 11 August 2014; Accepted 12 November 2014; Published 1 December 2014

Academic Editor: Chong Lin

Copyright ( 2014 L.-H. Chen and C.-N. Chen. This is an open access article distributed under the Creative Commons Attribution License, which permits unrestricted use, distribution, and reproduction in any medium, provided the original work is properly cited.

Responding to customer needs is important for business success. Quality function deployment provides systematic procedures for converting customer needs into technical requirements to ensure maximum customer satisfaction. The existing literature mainly focuses on the achievement of maximum customer satisfaction under a budgetary limit via mathematical models. The market goal of the new product for the target market segment is usually ignored. In this study, the proposed approach thus considers the target customer satisfaction degree for the target market segment in the model by formulating the overall customer satisfaction as a function of the quality level. In addition, the proposed approach emphasizes the cost-effectiveness concept in the design stage via the achievement of the target customer satisfaction degree using the minimal total cost. A numerical example is used to demonstrate the applicability of the proposed approach and its characteristics are discussed.

\section{Introduction}

In a fast-changing business environment, business units must invent new products or improve the quality of products continually to meet customer needs. The introduction of new products into the market to respond to customer demands is important for business success. From a marketing perspective, market segmentation is a necessary means for finding target customers. The new products should be positioned at the target customers during the product positioning process. The target customer satisfaction level for product quality should then be determined to meet the target customer requirements. To do this, a systematic new product development (NPD) process is usually carried out by business units to design an appropriate product that achieves the determined target customer satisfaction level based on a limited budget or using the minimum cost expenditure.

Quality function deployment (QFD) has been widely adopted by practitioners since the 1970s to design new products or improve existing ones [1]. Besides product development/design, QFD has been applied to fields such as quality management/planning, decision-making, manufacturing, service, and education [2]. QFD provides a systematic procedure for converting customer needs into technical requirements to ensure customer satisfaction. A number of researchers have proposed various quantitative approaches for applying QFD to a variety of problems. Among quantitative approaches, mathematical programming is usually applied to construct models to find the optimum design requirements for maximizing customer satisfaction under the limits of budget, time, and/or other resources [3$14]$.

For developing new products, the quality level is usually determined by the R\&D team to achieve the anticipated satisfaction degree of the target customers. However, the existing literature related to quantitative approaches for applying QFD in NPD processes focuses on finding the optimal solutions of design requirements for maximizing customer satisfaction under a budgetary limitation, not for achieving the desired customer satisfaction level in terms of product quality. Thus, the determined quality level of new products may not meet customer requirements so that the business unit may lose its competitive advantage in the market. In addition, the relationship between customer satisfaction and quality level for target customers is important for the developments of new products to determine the quality level in order to 
achieve the target customer satisfaction. Nevertheless, such a relationship is not incorporated in existing QFD models. Based on the above considerations, how to use the minimal budget/resources to achieve the quality level in order to meet the desired customer satisfaction should be considered in QFD-related problems. In this regard, instead of considering the budget constraint, this paper takes into account the relationship between customer satisfaction and quality level for the target customers in the QFD model to satisfy the desired satisfaction level in which the minimum design cost is achieved.

The rest of this paper is organized as follows. Section 2 briefly introduces the concept of QFD and the related normalization formulations, which are used in the proposed model. From a marketing perspective, the relationship between customer satisfaction and quality level for target customers is described in Section 3. In Section 4, considering the desired customer satisfaction and the corresponding quality level for target customers as constraints, a nonlinear mathematical programming model is proposed to minimize the total design cost. Section 5 provides an illustrative example of new bike design to demonstrate the feasibility and applicability of the proposed approach. Numerical analyses of the design parameters in the proposed model are also made to explore the characteristics of the model and their managerial implications. Finally, conclusions are provided in the final section.

\section{Background}

The basic concept of QFD is to transform customer voices into technical requirements to ensure customer satisfaction. The QFD processes are performed by applying the design information embodied in the relation matrix, called the house of quality (HOQ), as illustrated in Figure 1. In practice, QFD transforms customer needs into technical (or design/engineering) characteristics via the HOQ during the design or planning stage. The interior of the HOQ matches customer requirements (CRs) with the corresponding design requirements (DRs), identifying the relational intensity between each pair of CRs and DRs to ensure quality performance that can satisfy the target customers. If necessary, the roof of the $\mathrm{HOQ}$, represented as a correlation matrix, is constructed to indicate the technical correlations among DRs. Figure 1 shows a HOQ example to signify the relational intensities between CRs and DRs as well as the correlation degrees among DRs. The importance degree of each $\mathrm{CR}$ is also displayed in the figure. In general, the $\mathrm{HOQ}$ contains the relational intensity between each pair of CRs and DRs and the technical correlation between each pair of DRs. The legend in Figure 1 shows various designated symbols used to represent different degrees of relational intensity or technical correlation in the HOQ.

In general, the design information contained in the HOQ is integrated to further determine the importance of DRs and their achievement degrees in order to optimally satisfy customer satisfaction. To do this, a normalization process is usually applied by QFD researchers and practitioners. In the literature, the normalization model proposed by Wasserman

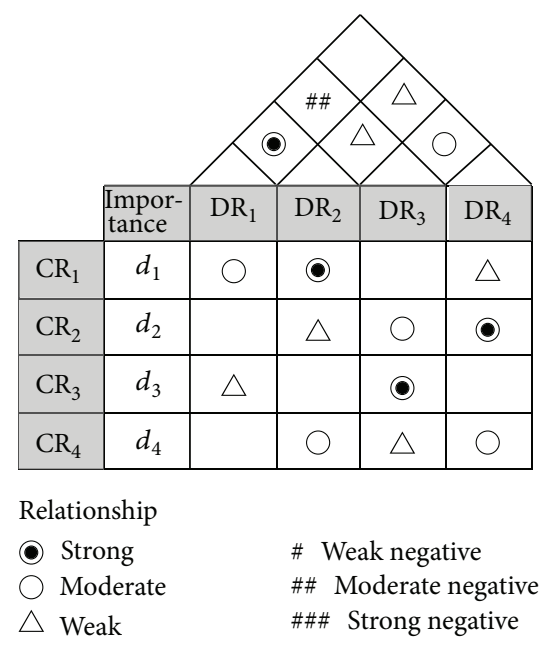

Figure 1: Matrix structure of HOQ.

[3] has been widely adopted (e.g., [6, 7, 9, 10, 13, 15-29]). Based on Lyman's normalization concept [30], this model is developed by incorporating the correlations among DRs, formulated as

$$
R_{i j}^{\prime}=\frac{\sum_{k=1}^{n} R_{i k} \cdot \gamma_{k j}}{\sum_{j=1}^{n} \sum_{k=1}^{n} R_{i k} \cdot \gamma_{k j}}
$$

from the vector space concept, where $\gamma_{k j}$ denotes the technical correlation between $\mathrm{DR}_{k}$ and $\mathrm{DR}_{j}$. In the above equation, $R_{i k}$ indicates the relational intensity between $\mathrm{CR}_{i}$ and $\mathrm{DR}_{k}$, which is measured based on a 3-point scale, such as 1-3-9 or 1-5-9, for describing the weak-moderate-strong relationship. Although Wasserman's normalization model has been widely adopted, it has some weaknesses. For example, it assumes that customer requirements are mutually independent. However, this may not be true in practice. More importantly, this model may generate a relational intensity for a pair of CRs and DRs that does not exist in the original design information. The model may thus produce unreasonable outcomes.

Identifying such weaknesses in Wasserman's normalization model, L.-H. Chen and C.-N. Chen [31] proposed the following modified normalization model:

$$
R_{i j}^{\mathrm{norm}}=\frac{\left(\sum_{k=1}^{n} \gamma_{k j}\right) R_{i j}}{\sum_{j=1}^{n}\left(\sum_{k=1}^{n} \gamma_{k j}\right) R_{i j}},
$$

where $R_{i j}^{\text {norm }}$ denotes the normalized relationship between $\mathrm{CR}_{i}$ and $\mathrm{DR}_{j}$. Applying the above modified normalization model to integrate design information, the unreasonable outcomes from Wasserman's model can be avoided. Furthermore, considering the possibility that some CRs are correlated, as shown in Figure 2, L.-H. Chen and C.-N. Chen [31] also proposed the following normalization model to integrate CRs, similar to that in (2), in determining the normalized weights of CRs:

$$
d_{i}^{\text {norm }}=\frac{\left(\sum_{l=1}^{m} \beta_{i l}\right) d_{i}}{\sum_{i=1}^{m}\left(\sum_{l=1}^{m} \beta_{i l}\right) d_{i}},
$$




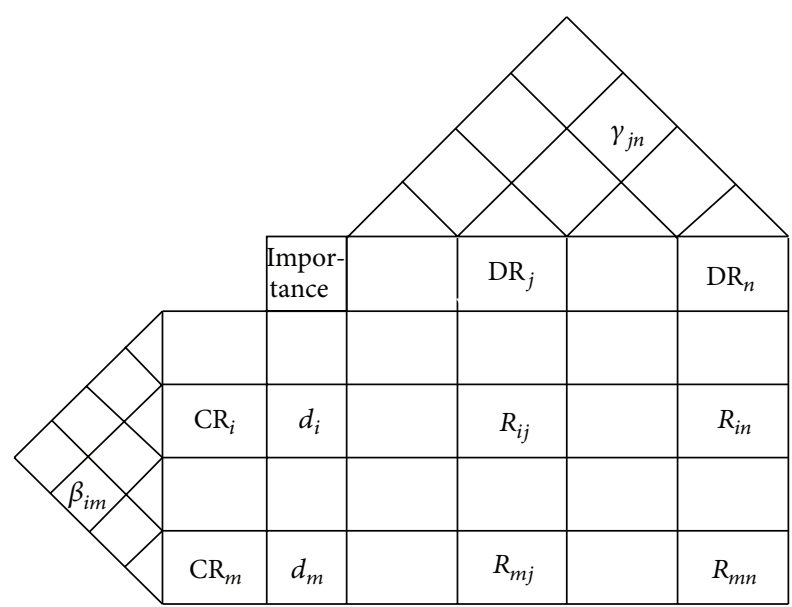

FIGURE 2: General HOQ structure.

where $\beta_{i l}$ denotes the correlation between $\mathrm{CR}_{i}$ and $\mathrm{CR}_{l}$ and $d_{i}$ is the importance of $\mathrm{CR}_{i}$. It is noted that the normalized weight $d_{i}^{\text {norm }}$ in (3) is reduced to $d_{i}$ when CRs are mutually independent; that is, $\sum_{l=1}^{m} \beta_{i l}=1$.

\section{Satisfaction Function with Quality Level}

The purpose of the development of new products or the improvement of existing products is mainly to satisfy customer needs or enhance customer satisfaction. Achieving customer satisfaction is always one of the main goals for the target market [32]. Customer satisfaction is considered one of the most important constructs for consumers [33]. Hence, customer satisfaction is important in marketing because of its great influence on customer purchase behavior. Based on an empirical study, Anderson and Sullivan [34] found that customer satisfaction can generally be described as a function of perceived quality from customers, considering an adjustment amount to reflect the customer perception of confirmation/disconfirmation. In their study, the customer satisfaction function is expressed as a concave down function of perceived quality. Following the concept of Anderson and Sullivan's study [34], the present study considers that customer satisfaction is positively related to the design quality of the product in terms of a concave down function, assuming that the quality designed for the product in the design stage will be perceived by the target customers in the future market; that is, the design quality level has a positive relationship with customer perceived quality. Figure 3 shows customer satisfaction (CS) as a concave down function of design quality (DQ).

For QFD applications, the design quality level of a product can be treated as the fulfillment level of design requirements (DRs), and therefore customer satisfaction can be described as a function of the DRs' fulfillment levels in the QFD processes. Let $C_{j}$ represent the cost required for $\mathrm{DR}_{j}$ with which the technical requirement for $\mathrm{DR}_{j}$ can be completely attained so that customer satisfaction can be fully achieved; $x_{j}(\in[0,1])$ represents the decision variable taking the fulfillment level of the technical requirement for $\mathrm{DR}_{j}$,

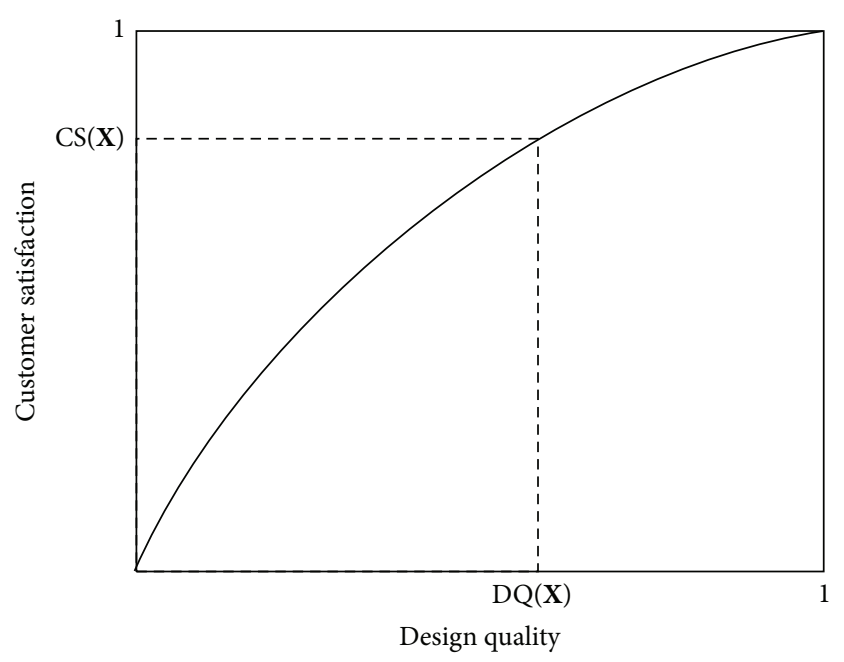

FIGURE 3: Functional curve for customer satisfaction (CS) and design quality (DQ).

denoting the quality level of $\mathrm{DR}_{j}$ required to meet the desired customer satisfaction. For simplification, suppose that the cost required to achieve the fulfillment level of $\mathrm{DR}_{j}, x_{j}$, is $C_{j} x_{j}$, that is, a proportional relation between the required cost and the fulfillment level. The value of $x_{j}=0$ means that the technical need for $\mathrm{DR}_{j}$ is only the basic requirement so that the cost is 0 . In addition, the use of the whole budget $C_{j}$ for $\mathrm{DR}_{j}$ will achieve the full technical requirement, that is, $x_{j}=1$, and full customer satisfaction for this DR.

Let $\mathbf{X}=\left[x_{1}, x_{2}, \ldots, x_{n}\right]^{T}$ be the vector containing the fulfillment levels of the technical requirements for all DRs. For a new product, the overall DQ is defined as the average of the fulfillment levels of all DRs as

$$
\mathrm{DQ}(\mathbf{X})=\frac{1}{n} \sum_{j=1}^{n} x_{j}, \quad 0 \leq x_{j} \leq 1,
$$

where $0 \leq \mathrm{DQ}(\mathbf{X}) \leq 1$. In other words, $x_{j}$ is interpreted as the design quality level of $\mathrm{DR}_{j}$. In addition, based on previous studies (e.g., [3-14]), using the normalized information from the HOQ, $R_{i j}^{\text {norm }}$ and $d_{i}^{\text {norm }}$ in (2) and (3), respectively, the customer satisfaction can be formulated as

$$
\mathrm{CS}(\mathbf{X})=\sum_{i=1}^{m} d_{i}^{\text {norm }} \sum_{j=1}^{n} R_{i j}^{\text {norm }} \cdot x_{j}, \quad 0 \leq x_{j} \leq 1,
$$

where $0 \leq \mathrm{CS}(\mathbf{X}) \leq 1$. It is obvious that $\mathrm{DQ}(\mathbf{X})=1$ and $\operatorname{CS}(\mathbf{X})=1$ when $x_{j}=1, \forall j=1,2, \ldots, n$. As described above, based on the concept of Anderson and Sullivan's study [34], customer satisfaction is characterized as a concave down function of the design quality of a product for a specific market segment. Figure 3 shows such a function. The concave down curve illustrates the diminishing marginal effect; as design quality increases, the marginal effect of customer satisfaction decreases. This is characterized here using the following simple equation:

$$
\mathrm{CS}(\mathbf{X})=[\mathrm{DQ}(\mathbf{X})]^{1 / k},
$$


where $k(>1)$ is a characteristic parameter used to describe the customer preference of a specific market segment for the design quality level of a specific product. The function in (6) characterizes features of the relationship between $\mathrm{CS}(\mathbf{X})$ and $\mathrm{DQ}(\mathbf{X})$, as described above. In practice, if the desired customer satisfaction degree is determined as the goal of satisfying the target market, (6) is employed to transform the desired value $\operatorname{CS}(\mathbf{X})$ into the corresponding value $\mathrm{DQ}(\mathbf{X})$ as the required design quality level.

\section{Proposed QFD Budget Planning Model}

In contrast to previous QFD-related studies that maximized customer satisfaction under a limited budget, this paper aims to find the minimum design budget to achieve the market goal in terms of the target customer satisfaction. To this end, some constraints are considered in the model. Based on (6), the target design quality level $\alpha(0<\alpha \leq 1)$ corresponding to the target customer satisfaction $\delta(0<\delta \leq 1)$ is determined by the management; that is, $\alpha=\delta^{k}, k>1$. The achieved customer satisfaction, formulated as (5), based on the fulfillment level of the technical requirement, that is, the fulfilled design quality level, for each DR, should not be less than the target customer satisfaction $\delta$; similarly, the fulfilled overall design quality of (4) should not be less than the target design quality level $\alpha$. More importantly, the fulfilled overall design quality should not be less than the quality level reflected by the achieved customer satisfaction for the target market in (6); that is, $(1 / n) \sum_{j=1}^{n} x_{j} \geq\left(\sum_{i=1}^{m} d_{i}^{\text {norm }} \sum_{j=1}^{n} R_{i j}^{\text {norm }}\right.$. $\left.x_{j}\right)^{k}$. The right-hand side in the above inequality relation can be interpreted as the product quality perceived by the target customers, since it is derived based on the relations between CRs and DRs in the HOQ. Thus, this constraint ensures that the realized overall quality achieved from the product design is better than or equal to that perceived by the target customers.

In addition to the restrictions on the target design quality level and customer satisfaction, from the designers' viewpoint, in general there is a minimum satisfaction level for each customer requirement $\mathrm{CR}_{i}$. The constraint of $\sum_{j=1}^{n} R_{i j}^{\mathrm{norm}} \cdot x_{j} \geq$ $\varepsilon_{i}, 0<\varepsilon_{i} \leq 1, i=1, \ldots, m$, reflects this condition, where $\varepsilon_{i}$ can be determined based on the normalized weights of $\mathrm{CR}_{i}$ using the equation $\varepsilon_{i}=t_{1} d_{i}^{\text {norm }}, t_{1}>0$, to reveal each CR's importance. The fulfilled design quality level for each $\mathrm{DR}_{j}, x_{j}$, is usually required to not be less than a minimum level, say $\rho_{j}$, $0<\rho_{j} \leq 1$, where $\rho_{j}$ can be set as $\rho_{j}=t_{2}\left(\sum_{i=1}^{m} d_{i}^{\text {norm }} \cdot R_{i j}^{\text {norm }}\right) \alpha$, $t_{2}>0$, considering the normalized importance of $\mathrm{DR}_{j}$ and the target design quality level $\alpha$. Note that the parameters $t_{1}$ and $t_{2}$ can be determined subjectively by the management in weighing the corresponding CRs and DRs, respectively, under the constraints of $0<\varepsilon_{i} \leq 1$ and $0<\rho_{j} \leq 1$.

A nonlinear programming model is formulated in (7), in which constraints $(7 \mathrm{a})$ to $(7 \mathrm{~g})$ are used for the specifications described above. The objective function (7) in the model reflects the proportional relation between the required cost and the fulfillment level of each DR.
Proposed Nonlinear Programming Model. Consider

$$
\operatorname{Min} \sum_{j=1}^{n} C_{j} x_{j}
$$

subject to

$$
\begin{gathered}
\sum_{i=1}^{m} d_{i}^{\text {norm }} \sum_{j=1}^{n} R_{i j}^{\text {norm }} \cdot x_{j} \geq \delta, \quad 0<\delta \leq 1 \\
\sum_{j=1}^{n} x_{j} \geq n \alpha, \quad 0<\alpha \leq 1 \\
\frac{1}{n} \sum_{j=1}^{n} x_{j}-\left(\sum_{i=1}^{m} d_{i}^{\text {norm }} \sum_{j=1}^{n} R_{i j}^{\text {norm }} \cdot x_{j}\right)^{k} \geq 0, \quad k>1 \\
\sum_{j=1}^{n} R_{i j}^{\text {norm }} \cdot x_{j} \geq \varepsilon_{i}, \quad 0<\varepsilon_{i} \leq 1, i=1,2, \ldots, m \\
\rho_{j} \leq x_{j} \leq 1, \quad 0<\rho_{j} \leq 1, \quad j=1,2, \ldots, n \\
\rho_{j}=t_{2}\left(\sum_{i=1}^{m} d_{i}^{\text {norm }} \cdot R_{i j}^{\text {norm }}\right) \alpha .
\end{gathered}
$$

It is noted that constraint $(7 \mathrm{a})$ can be represented as

$$
\sum_{j=1}^{n}\left(\sum_{i=1}^{m} d_{i}^{\mathrm{norm}} \cdot R_{i j}^{\mathrm{norm}}\right) \cdot x_{j} \geq \delta, \quad 0<\delta \leq 1 .
$$

If the normalized importance of $\mathrm{DR}_{j}$ to the contribution of all CRs, $w_{j}^{\text {norm }}$, is defined as

$$
w_{j}^{\mathrm{norm}}=\sum_{i=1}^{m} d_{i}^{\mathrm{norm}} \cdot R_{i j}^{\mathrm{norm}},
$$

where $\sum_{j=1}^{n} w_{j}^{\text {norm }}=1$, then $(7 \mathrm{a})$ and $(7 \mathrm{~g})$ can be, respectively, expressed as

$$
\begin{gathered}
\sum_{j=1}^{n} w_{j}^{\text {norm }} \cdot x_{j} \geq \delta, \quad 0<\delta \leq 1, \\
\rho_{j}=t_{2} w_{j}^{\text {norm }} \alpha .
\end{gathered}
$$

In (6), parameter $k$ is important as it specifies the relation between the target design quality level and the target customer satisfaction and the relation between the fulfilled overall design quality and the quality level reflected by the achieved customer satisfaction, that is, the perceived quality level. As mentioned, parameter $k$ is related to the customer behavior of a specific market segment for a specific product. The value of $k$ can be either determined subjectively by the management or obtained using quantitative approaches. To do this, the simple regression approach is suggested in this paper. Under the consideration that customer satisfaction is 
a concave down function of the perceived quality level of the product, a linearly transformed function can be expressed as $\ln \alpha=k \ln \delta$. Using a group of paired estimations $\left(\alpha_{i}, \delta_{i}\right)$ based on the experience and knowledge from the QFD team members and/or managers of the marketing department, the simple regression function $\ln \delta=(1 / k) \ln \alpha$ can be constructed to determine the $k$ value.

The procedure for applying the proposed model is as follows.

Step 1. Determine the desired product to be developed or improved for the target market segment.

Step 2. Construct the corresponding HOQ to reflect the relations between CRs and DRs.

Step 3. Integrate the basic design information in the HOQ to obtain the normalized values $R_{i j}^{\text {norm }}, d_{i}^{\text {norm }}$, and $w_{j}^{\text {norm }}$ using the normalization model in (2) (and (3), if needed).

Step 4. Considering that $\delta$ is a concave down function of $\alpha$, subjectively determine the value of $k$ for meeting the relationship $\alpha=\delta^{k}, k>1$. Alternatively, collect a group of paired estimations $\left(\alpha_{i}, \delta_{i}\right), \forall \alpha_{i}, \delta_{i} \in[0,1]$, for the desired product in the target market segment. Decide the parameter $k(>1)$ in $\ln \delta=(1 / k) \ln \alpha$ by applying a simple regression analysis.

Step 5. Determine the target customer satisfaction $\delta$ for NPD based on the target market segment and then obtain the target design quality level $\alpha$ based on $\alpha=\delta^{k}$ using the $k$ value determined in Step 4.

Step 6. Let management subjectively decide the values of parameters $t_{1}$ and $t_{2}$.

Step 7. Construct the proposed nonlinear programming model using the integrated information from the HOQ obtained in Step 2.

Step 8. Solve the model to find the optimal design quality level of each DR so that the target customer satisfaction is achieved for the target market with the minimum budget.

\section{Numerical Illustration}

This section demonstrates the applicability of the proposed approach using a constructed example of a manufacturer of bicycles. Based on this example, parameter analyses are provided to further illustrate the proposed approach.

5.1. Example. With rising awareness of environmental protection, the municipal government has encouraged citizens to take mass transportation to work. The marketing department of the bicycle firm has observed that an increasing number of citizens are willing to bike the short distance between home and mass transportation stations. Therefore, the marketing department plans to launch a new bike to cater to this trend. For this plan, an important issue for the NPD project team is to determine the minimum budget needed to achieve the market goal of the NPD during the design stage.

Firstly, the newly developed bike is positioned as simple and easy for biking the short distance between home and mass transportation station and aims to satisfy commuters. The NPD team selects QFD as the design platform. In the second step, the HOQ is constructed for specifying the relations between CRs and DRs. The following six basic requirements are identified: (1) ride comfort, (2) ride safety, (3) easy handling, (4) easy movement, (5) low maintenance, and (6) durability. Based on consensus, the team members propose nine design requirements that correspond to the six basic customer requirements. The nine design requirements are (1) frame, (2) suspension, (3) derailleur, (4) brake, (5) wheels, (6) handlebars, (7) saddle, (8) pedals, and (9) total weight. The degree of relational intensity for the relationship between CRs and DRs is defined by weak-moderate-strong; the correlation among CRs or among DRs is also defined by weak-moderatestrong, but allowing for negative correlations. Furthermore, the NPD team identifies the CRs' importance degrees for the product to emphasize its easy handling and ride safety. The basic QFD design information for the product is shown in Figure 4.

The main work in the third step is to integrate the design information into the HOQ to obtain the normalized relation strengths or weights, namely $R_{i j}^{\text {norm }}, d_{i}^{\text {norm }}$, and $w_{j}^{\text {norm }}$, for establishing the proposed nonlinear programming model to achieve the market/quality goal at the minimum design cost. As described before, L.-H. Chen and C.-N. Chen's normalization models, (2) and (3), are employed. To do this, the degree of relational or correlation intensity described as weak-moderate-strong must be numerically scaled. As commonly used in the literature, the rating scale 1-3-9 is employed for relational intensity, that is, weak-moderatestrong, between CRs and DRs, and $\pm(0.1-0.3-0.9)$ is used for correlation, that is, weak-moderate-strong, among CRs or among DRs with negative correlations allowed. Figure 5 shows the normalized results for the product using the basic design information in Figure 4.

After the integrated information from the HOQ has been obtained, the characteristic parameter $k$ for the market segment of commuters should be determined to characterize the functional curve between customer satisfaction and design quality level. Based on the experience of the marketing experts, $k$ is set to 2 , that is, $\operatorname{CS}(\mathbf{X})=[\mathrm{DQ}(\mathbf{X})]^{1 / 2}$, as shown in Figure 6. Based on the determined function, the fifth step is to set up the target design quality level $\alpha$. From a market competitive analysis, the target customer satisfaction is set as $\delta=0.8$, so the target design quality level $\alpha$ is obtained as 0.64 based on the function $\alpha=\delta^{k}, k=2$. To formulate the proposed nonlinear programming model for the minimum cost in the sixth step, the parameters $t_{1}$ and $t_{2}$ should be determined to specify the minimum satisfaction level for each customer requirement $\mathrm{CR}_{i}$ and the minimum design quality level for each $\mathrm{DR}_{j}$. The values $t_{1}=3$ and $t_{2}=3$ are set by the NPD team in this example.

Based on the settings in the previous steps, the proposed nonlinear programming model can be formulated for 


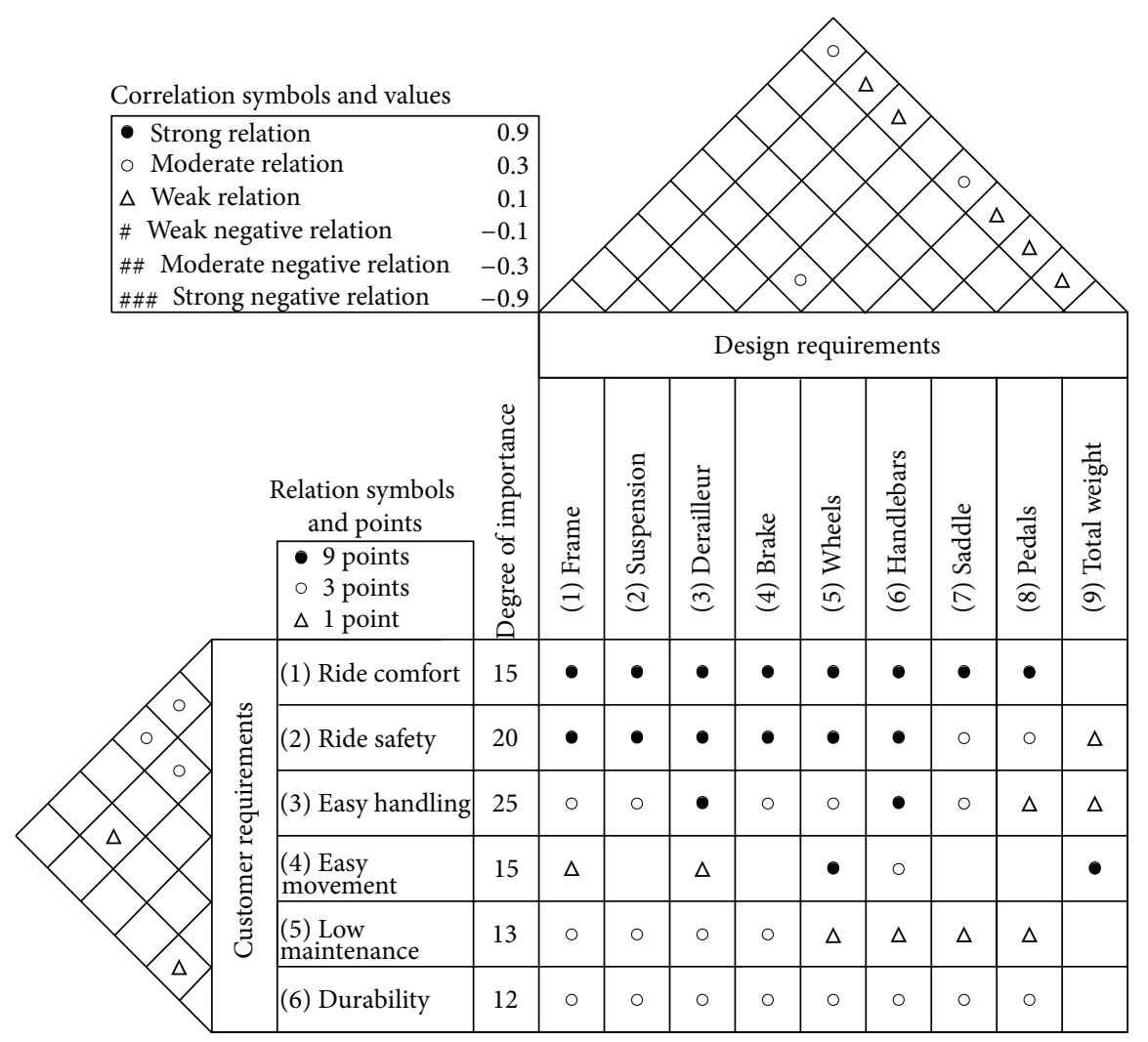

FIGURE 4: Basic QFD design information for product.

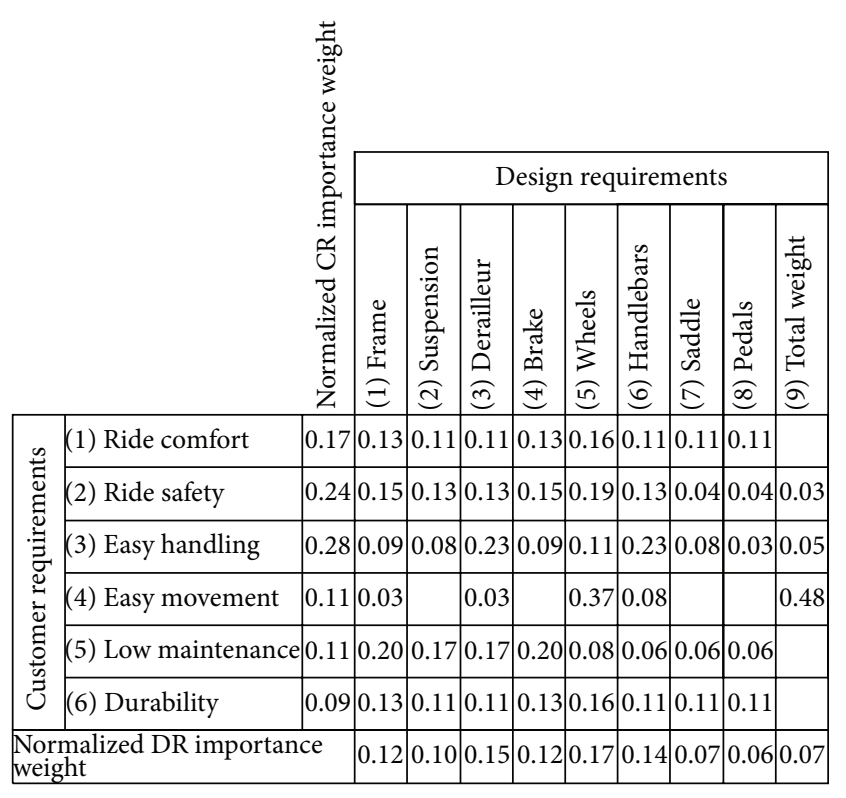

FIGURE 5: Normalized results for product.

the minimum design cost. Let the decision variable $x_{j}, j=$ $1,2, \ldots, 9$, represent the technical fulfillment level of $\mathrm{DR}_{j}$. The model aims to achieve the target customer satisfaction $(\delta=0.8)$ and the target design quality levels $(\alpha=0.64)$ for the product at the minimum total design cost, $\sum_{j=1}^{9} C_{j} x_{j}$,

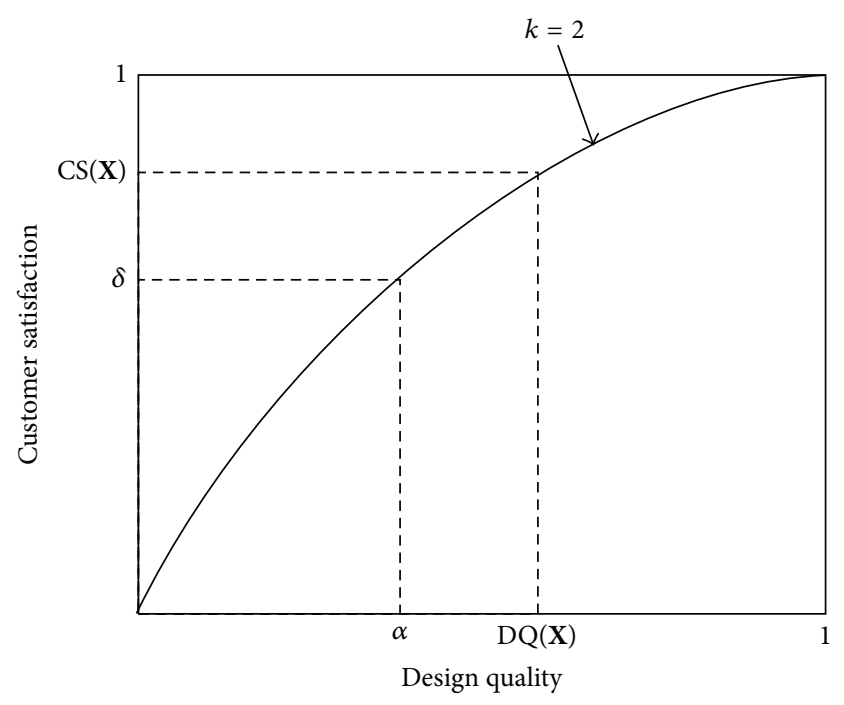

FIGURE 6: Functional curve of customer satisfaction for product.

where $C_{j}$ denotes the design cost of completely fulfilling the technical level of $\mathrm{DR}_{j}$. The nonlinear programming model is expressed as

$$
\operatorname{Min} \sum_{j=1}^{9} C_{j} x_{j}
$$


subject to

$$
\begin{aligned}
& 0.12 x_{1}+0.10 x_{2}+0.15 x_{3}+0.12 x_{4}+0.17 x_{5} \\
& +0.14 x_{6}+0.07 x_{7}+0.06 x_{8}+0.07 x_{9} \geq 0.8 \\
& x_{1}+x_{2}+x_{3}+x_{4}+x_{5}+x_{6}+x_{7}+x_{8}+x_{9} \geq 9 \times 0.64 \\
& \frac{1}{9}\left(x_{1}+x_{2}+x_{3}+x_{4}+x_{5}+x_{6}+x_{7}+x_{8}+x_{9}\right) \\
& -\left(0.12 x_{1}+0.10 x_{2}+0.15 x_{3}+0.12 x_{4}+0.17 x_{5}\right. \\
& \left.+0.14 x_{6}+0.07 x_{7}+0.06 x_{8}+0.07 x_{9}\right)^{2} \geq 0 \\
& 0.13 x_{1}+0.11 x_{2}+0.11 x_{3}+0.13 x_{4}+0.16 x_{5} \\
& +0.11 x_{6}+0.11 x_{7}+0.11 x_{8}+0.00 x_{9} \geq 0.51 \\
& 0.15 x_{1}+0.13 x_{2}+0.13 x_{3}+0.15 x_{4}+0.19 x_{5} \\
& +0.13 x_{6}+0.04 x_{7}+0.04 x_{8}+0.03 x_{9} \geq 0.72 \\
& 0.09 x_{1}+0.08 x_{2}+0.23 x_{3}+0.09 x_{4}+0.11 x_{5} \\
& +0.23 x_{6}+0.08 x_{7}+0.03 x_{8}+0.05 x_{9} \geq 0.84 \\
& 0.03 x_{1}+0.00 x_{2}+0.03 x_{3}+0.00 x_{4}+0.37 x_{5} \\
& +0.08 x_{6}+0.00 x_{7}+0.00 x_{8}+0.48 x_{9} \geq 0.33 \\
& 0.20 x_{1}+0.17 x_{2}+0.17 x_{3}+0.20 x_{4}+0.08 x_{5} \\
& +0.06 x_{6}+0.06 x_{7}+0.06 x_{8}+0.00 x_{9} \geq 0.33 \\
& 0.13 x_{1}+0.11 x_{2}+0.11 x_{3}+0.13 x_{4}+0.16 x_{5} \\
& +0.11 x_{6}+0.11 x_{7}+0.11 x_{8}+0.00 x_{9} \geq 0.27 \\
& 0.23 \leq x_{1} \leq 1 \\
& 0.19 \leq x_{2} \leq 1 \\
& 0.29 \leq x_{3} \leq 1 \\
& 0.23 \leq x_{4} \leq 1 \\
& 0.33 \leq x_{5} \leq 1 \\
& 0.27 \leq x_{6} \leq 1 \\
& 0.13 \leq x_{7} \leq 1 \\
& 0.12 \leq x_{8} \leq 1 \\
& 0.13 \leq x_{9} \leq 1 \text {. }
\end{aligned}
$$

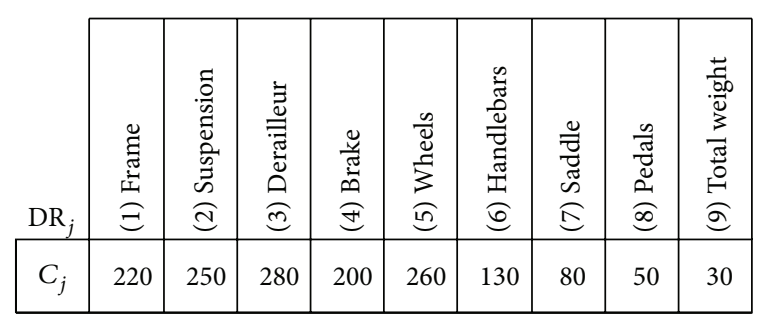

Unit: \$ thousand

Figure 7: Completely fulfilled design $\operatorname{cost} C_{j}$ for $\mathrm{DR}_{j}$.

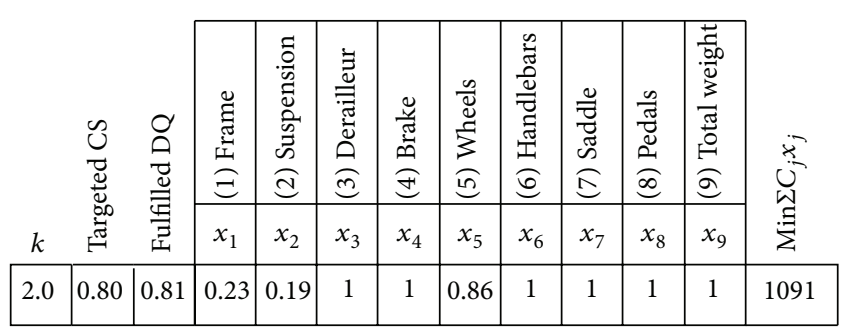

FIgURE 8: Optimal technical fulfillments for product.

To solve the model, the design cost $C_{j}$ for $\mathrm{DR}_{j}$ must be determined beforehand. For this example, the costs are provided by the NPD team, as shown in Figure 7. The proposed nonlinear model can be solved using commercial software such as LINGO 11.0. Figure 8 summarizes the optimal technical fulfillment level $x_{j}$ for each $\mathrm{DR}_{j}$. The minimum total design cost for the product is $\$ 1,091,000$. The figure indicates that the target customer satisfaction can be achieved at $\operatorname{CS}(\mathbf{X})=\sum_{j=1}^{9} w_{j}^{\text {norm }} \cdot x_{j}=0.8$. The fulfilled design quality level is determined as $\mathrm{DQ}(\mathbf{X})=(1 / 9) \sum_{j=1}^{9} x_{j}=0.81$, which is greater than $\alpha(=0.64)$, satisfying constraint $(7 \mathrm{~b})$. The solutions obtained in Figure 8 satisfy the requirements of the new product for the target customer satisfaction at the minimum total design cost.

5.2. Parameter Analyses. The proposed nonlinear programming model includes three design parameters, namely, $k$, $t_{1}$, and $t_{2}$, that are specified by the NPD team. These three parameters affect the design quality level and therefore the total design cost. The influence of the combination of different values of $k, t_{1}$, and $t_{2}$ on the total design cost was thus examined. In the analyses, the target customer satisfaction, $\delta$, was set at $0.6,0.7$, and 0.8 , respectively. The results of the analyses are summarized below.

(1) The parameter $k$ characterizes the customer satisfaction of the design quality level. The larger the value of $k$ is, the more attractive to customers the product quality level is. With a larger $k$, the target customer satisfaction can be achieved using only the lower level of product design quality, and therefore the total design cost is lower. As a demonstration, with $t_{1}$ and $t_{2}$ fixed at 3 , Figure 9 shows that the total design cost 


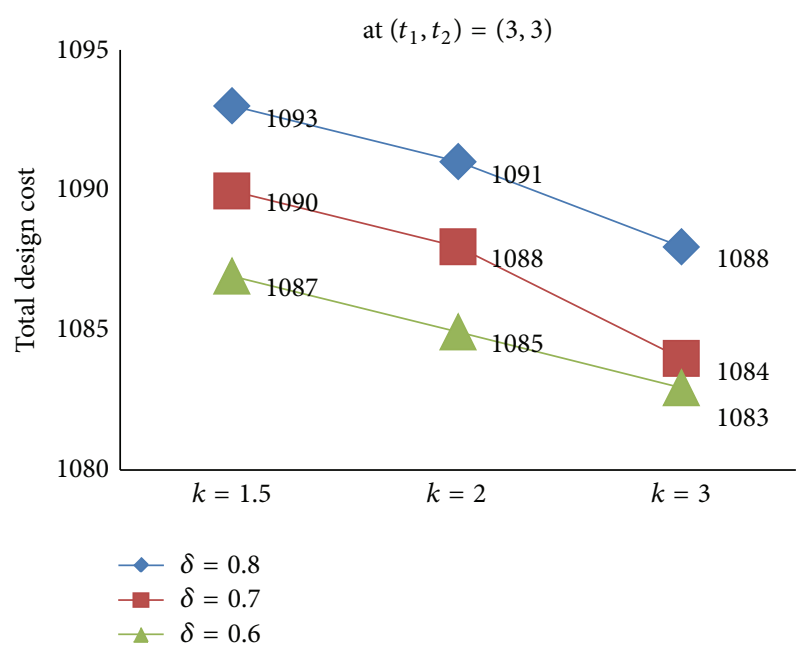

FIgURE 9: Variation of total design cost with $k$ for various $\delta$ values.

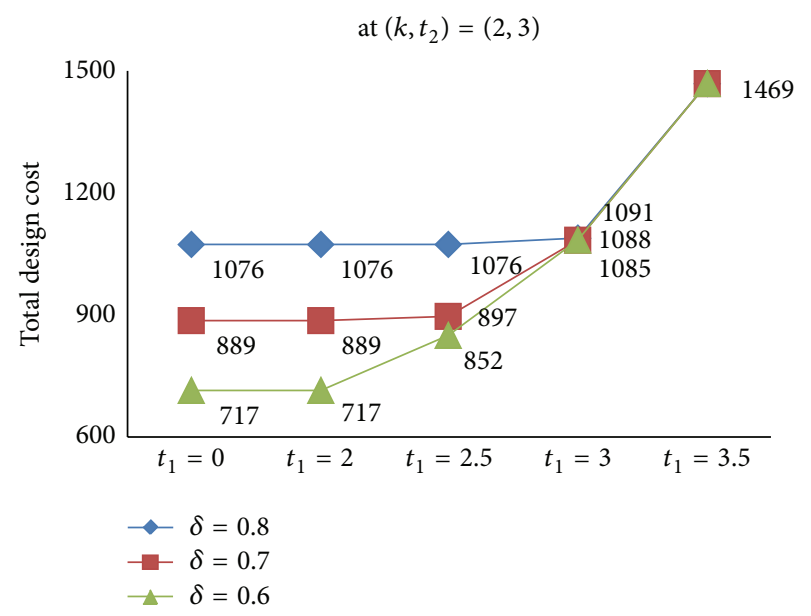

FIgURE 10: Variation of total design cost with $t_{1}$ for various $\delta$ values.

decreases with increasing $k$ value regardless of the target customer satisfaction, $\delta$.

(2) The $t_{1}$ and $t_{2}$ values in (7e) and (7g) affect the minimum satisfaction level for each customer requirement $\mathrm{CR}_{i}$ and the fulfilled minimum design quality level for each $\mathrm{DR}_{j}$, respectively, and therefore affect the total design cost. Larger values of $t_{1}$ and/or $t_{2}$ increase the total design cost. With $k=2$ and $t_{2}=3$, Figure 10 shows the impact of the $t_{1}$ value on the total design cost. The total design cost remains unchanged in a range of $t_{1}$ values that depends on $\delta$ because the fulfilled minimum design quality level $\rho_{j}$ at $t_{2}=3$ confines the influence of the minimum satisfaction level $\varepsilon_{i}$ on the total design cost at some levels of $t_{1}$ regardless of the target customer satisfaction level $\delta$. It is also noted that if the $t_{1}$ value is sufficiently large $\left(t_{1}=3.5\right)$ and $t_{2}=3$, the total design cost is the same (1469) for all three levels of the target

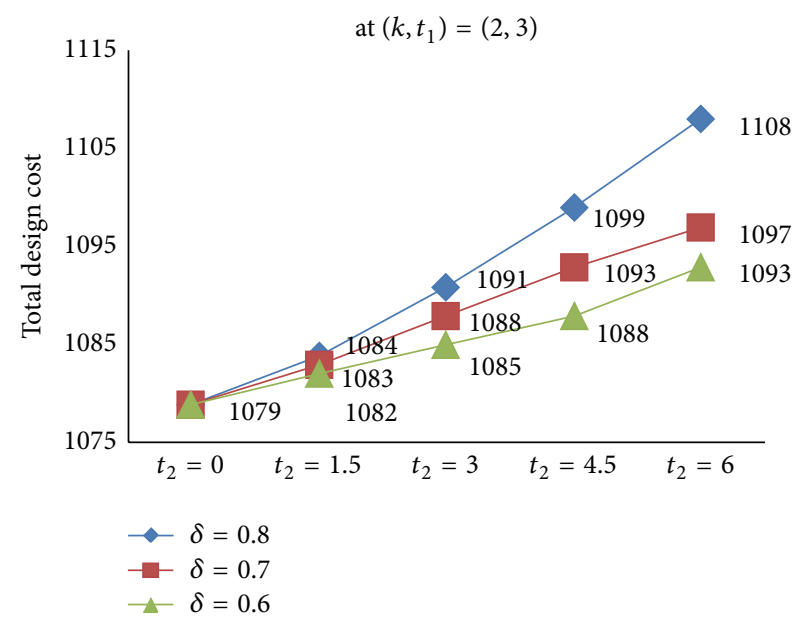

FIgURE 11: Variation of total design cost with $t_{2}$ for various $\delta$ values.

customer satisfaction, since the aggregated results from the required minimum satisfaction level for each customer requirement $\mathrm{CR}_{i}$ surpass each target customer satisfaction. The high required minimum satisfaction level due to $t_{1}=3.5$ resulted in the largest total design cost. With $k=2$ and $t_{1}=3$, the total design cost changes with $t_{2}$, as shown in Figure 11.

(3) From a design viewpoint, if the minimum satisfaction level for each customer requirement $\mathrm{CR}_{i}$ and the fulfilled minimum design quality level for each $\mathrm{DR}_{j}$ are not required, that is, $t_{1}$ and $t_{2}$ are fixed at 0 , the minimal total design cost can be obtained from the proposed model (7) at each setting of the targeted customer satisfaction level $\delta$. For example, with $t_{1}=$ $t_{2}=0$ and $\delta=0.6,0.7$, and 0.8 , respectively, the total design costs are 700,878 , and 1063 , respectively, regardless of the $k$ value. This indicates that to achieve the target degree of customer satisfaction for a certain market segment, the investment amount of the total design cost has the lowest bound.

\section{Conclusions}

A mathematical model was proposed for determining the design quality level required to achieve the target customer satisfaction for the target market segment with the minimum total design cost. In the proposed model, the customer satisfaction is expressed as a function of the quality level, considering the consumer behavior of the target market segment. Moreover, the proposed model allows the NPD team to set the minimum satisfaction level for each CR and/or the fulfilled minimum design quality level for each DR, making the design processes flexible. A numerical example was provided to demonstrate the feasibility and applicability of the proposed approach. In future research, the relation between customer satisfaction and quality level will be further investigated to make the proposed model more applicable in the real world. 


\section{Nomenclature}

$\mathrm{CR}_{i}$ : The $i$ th customer requirement

$\mathrm{DR}_{j}$ : The $j$ th design requirement

$R_{i j}$ : Relational intensity between $\mathrm{CR}_{i}$ and $\mathrm{DR}_{j}$

$\gamma_{k j}$ : Technical correlation between $\mathrm{DR}_{k}$ and

$\mathrm{DR}_{j}$

$R_{i j}^{\prime}$ : $\quad$ Normalized relational intensity between

$\mathrm{CR}_{i}$ and $\mathrm{DR}_{j}$ in Wasserman's normalization model

$R_{i j}^{\text {norm }}$ Normalized relational intensity between $\mathrm{CR}_{i}$ and $\mathrm{DR}_{j}$ in L.-H. Chen and C.-N. Chen's normalization model

$d_{i}$ : $\quad$ Original importance weight of $\mathrm{CR}_{i}$

$\beta_{i l}$ : $\quad$ Correlation between $\mathrm{CR}_{i}$ and $\mathrm{CR}_{l}$

$d_{i}^{\text {norm }}$ : Normalized importance weight of $\mathrm{CR}_{i}$ in L.-H. Chen and C.-N. Chen's integration model when CRs' correlations exist

$w_{j}^{\text {norm }}:$ Normalized importance weight of $\mathrm{DR}_{j}$

$C_{j}$ : $\quad$ Required cost for $\mathrm{DR}_{j}$ to fully achieve customer satisfaction

$x_{j}: \quad$ Technical fulfillment level for $\mathrm{DR}_{j}$

X: Design vector containing the fulfillment levels of all DRs

$\mathrm{DQ}(\mathbf{X})$ : Overall design quality level by design vector $\mathbf{X}$

CS(X): Fulfilled customer satisfaction by design vector $\mathbf{X}$

$\alpha: \quad$ Target design quality level

$\delta: \quad$ Target customer satisfaction

$k$ : The characteristic parameter to describe the customer preference of a specific market segment for the design quality level of a specific product

$\varepsilon_{i}: \quad$ Minimum required satisfaction level for $\mathrm{CR}_{i}$

$t_{1}$ : $\quad$ Design parameter to determine $\varepsilon_{i}$

$\rho_{j}$ : $\quad$ Minimum fulfilled quality level for $\mathrm{DR}_{j}$

$t_{2}$ : Design parameter to determine $\rho_{j}$.

\section{Conflict of Interests}

The authors declare that there is no conflict of interests regarding the publication of this paper.

\section{References}

[1] L. Cohen, Quality Function Deployment: How to Make QFD Work for You, Addison-Wesley, Reading, Mass, USA, 1995.

[2] L.-K. Chan and M.-L. Wu, "Quality function deployment: a literature review," European Journal of Operational Research, vol. 143, no. 3, pp. 463-497, 2002.

[3] G. S. Wasserman, "On how to prioritize design requirements during the QFD planning process," IIE Transactions, vol. 25, no. 3, pp. 59-65, 1993.

[4] K.-J. Kim, "Determining optimal design characteristic levels in quality function deployment," Quality Engineering, vol. 10, no. 2, pp. 295-307, 1997.
[5] H. Moskowitz and K.-J. Kim, "QFD optimizer: a novice friendly quality function deployment decision support system for optimizing product designs," Computers \& Industrial Engineering, vol. 32, no. 3, pp. 641-655, 1997.

[6] T. Park and K.-J. Kim, "Determination of an optimal set of design requirements using house of quality," Journal of Operations Management, vol. 16, no. 5, pp. 569-581, 1998.

[7] J. Bode and R. Y. K. Fung, "Cost engineering with quality function deployment," Computers and Industrial Engineering, vol. 35, no. 3-4, pp. 587-590, 1998.

[8] R. G. Askin and D. W. Dawson, "Maximizing customer satisfaction by optimal specification of engineering characteristics," IIE Transactions (Institute of Industrial Engineers), vol. 32, no. 1, pp. 9-20, 2000.

[9] R. Y. K. Fung, J. Tang, Y. Tu, and D. Wang, "Product design resources optimization using a non-linear fuzzy quality function deployment model," International Journal of Production Research, vol. 40, no. 3, pp. 585-599, 2002.

[10] L.-H. Chen and M.-C. Weng, "A fuzzy model for exploiting quality function deployment," Mathematical and Computer Modelling, vol. 38, no. 5-6, pp. 559-570, 2003.

[11] H. Iranmanesh and V. Thomson, "Competitive advantage by adjusting design characteristics to satisfy cost targets," International Journal of Production Economics, vol. 115, no. 1, pp. 64-71, 2008.

[12] L.-H. Chen and W.-C. Ko, "A fuzzy nonlinear model for quality function deployment considering Kano's concept," Mathematical and Computer Modelling, vol. 48, no. 3-4, pp. 581-593, 2008.

[13] L.-H. Chen and W.-C. Ko, "Fuzzy approaches to quality function deployment for new product design," Fuzzy Sets and Systems, vol. 160, no. 18, pp. 2620-2639, 2009.

[14] J.-H. Shin, H.-B. Jun, D. Kiritsis, and P. Xirouchakis, "A decision support method for product conceptual design considering product lifecycle factors and resource constraints," International Journal of Advanced Manufacturing Technology, vol. 52, no. 912, pp. 865-886, 2011.

[15] M. Braglia, G. Fantoni, and M. Frosolini, "The house of reliability," International Journal of Quality \& Reliability Management, vol. 24, no. 4, pp. 420-440, 2007.

[16] W.-C. Chiou, H.-W. Kuo, and I.-Y. Lu, "A technology oriented productivity measurement model," International Journal of Production Economics, vol. 60, pp. 69-77, 1999.

[17] P.-T. Chuang, "A QFD approach for distribution's location model," International Journal of Quality and Reliability Management, vol. 19, no. 8, pp. 1037-1054, 2002.

[18] L.-H. Chen and M.-C. Weng, "An evaluation approach to engineering design in QFD processes using fuzzy goal programming models," European Journal of Operational Research, vol. 172, no. 1, pp. 230-248, 2006.

[19] E. K. Delice and Z. Güngör, "A new mixed integer linear programming model for product development using quality function deployment," Computers \& Industrial Engineering, vol. 57, no. 3, pp. 906-912, 2009.

[20] E. K. Delice and Z. Güngör, "A mixed integer goal programming model for discrete values of design requirements in QFD," International Journal of Production Research, vol. 49, no. 10, pp. 2941-2957, 2011.

[21] F. Franceschini and S. Rossetto, "QFD: an interactive algorithm for the prioritization of product's technical design characteristics," Integrated Manufacturing Systems, vol. 13, no. 1, pp. 69-75, 2002. 
[22] C. H. Han, J. K. Kim, S. H. Choi, and S. H. Kim, "Determination of information system development priority using quality function deployment," Computers and Industrial Engineering, vol. 35, no. 1-2, pp. 241-244, 1998.

[23] E. E. Karsak, "Fuzzy multiple objective decision making approach to prioritize design requirements in quality function deployment," International Journal of Production Research, vol. 42, no. 18, pp. 3957-3974, 2004.

[24] X. Lai, M. Xie, and K. C. Tan, "Dynamic programming for QFD optimization," Quality and Reliability Engineering International, vol. 21, no. 8, pp. 769-780, 2005.

[25] S.-T. Liu, "Rating design requirements in fuzzy quality function deployment via a mathematical programming approach," International Journal of Production Research, vol. 43, no. 3, pp. 497513, 2005.

[26] R. Ramanathan and J. Yunfeng, "Incorporating cost and environmental factors in quality function deployment using data envelopment analysis," Omega, vol. 37, no. 3, pp. 711-723, 2009.

[27] H. Raharjo, M. Xie, and A. C. Brombacher, "A systematic methodology to deal with the dynamics of customer needs in Quality Function Deployment," Expert Systems with Applications, vol. 38, no. 4, pp. 3653-3662, 2011.

[28] Y.-M. Wang and K.-S. Chin, "Technical importance ratings in fuzzy QFD by integrating fuzzy normalization and fuzzy weighted average," Computers \& Mathematics with Applications, vol. 62, no. 11, pp. 4207-4221, 2011.

[29] Y.-M. Wang, "A fuzzy-normalisation-based group decisionmaking approach for prioritising engineering design requirements in QFD under uncertainty," International Journal of Production Research, vol. 50, no. 23, pp. 6963-6977, 2012.

[30] D. Lyman, "Deployment normalization," in Proceedings of the Transactions from the 2nd Symposium on Quality Function Deployment, pp. 307-315, Automotive Division of the American Society for Quality Control, The American Supplier Institute and GOAL/QPC, Dearborn, Mich, USA, 1990.

[31] L.-H. Chen and C.-N. Chen, "Normalisation models for prioritising design requirements for quality function deployment processes," International Journal of Production Research, vol. 52, no. 2, pp. 299-313, 2014.

[32] S. Erevelles and C. Leavitt, "A comparison of current models of consumer satisfaction/dissatisfaction," Journal of Consumer Satisfaction, Dissatisfaction and Complaining Behavior, vol. 5, pp. 104-114, 1992.

[33] M. J. Morgan, J. A. Attaway, and M. Griffin, "The role of product/service experience in the satisfaction formation process: a test of moderation," Journal of Consumer Satisfaction, Dissatisfaction and Complaining Behavior, vol. 9, pp. 391-405, 1996.

[34] E. W. Anderson and M. W. Sullivan, "The antecedents and consequences of customer satisfaction for firms," Marketing Science, vol. 12, no. 2, pp. 125-143, 1993. 


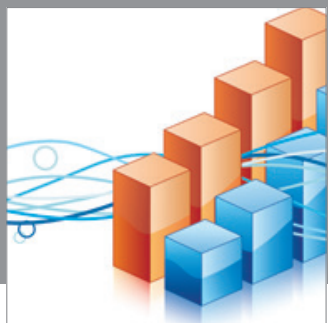

Advances in

Operations Research

mansans

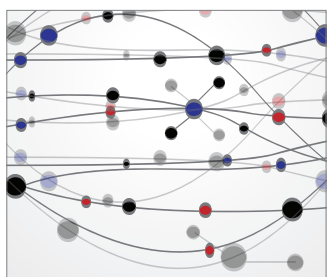

The Scientific World Journal
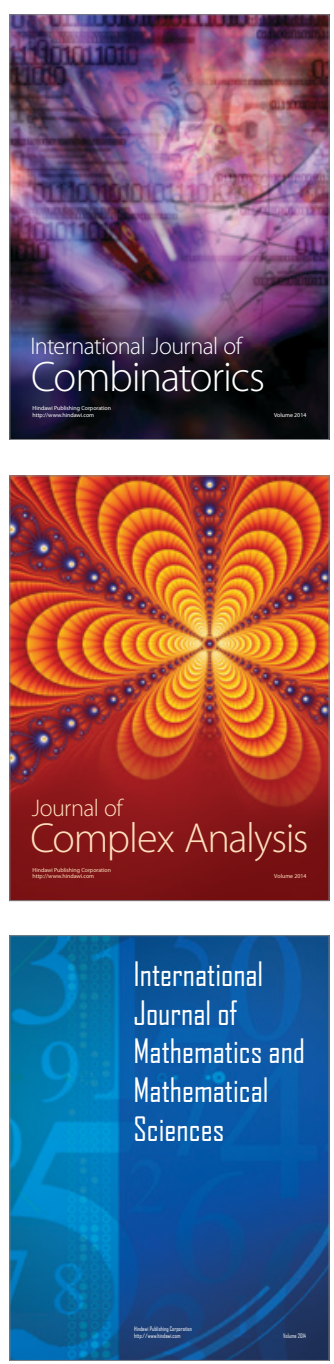
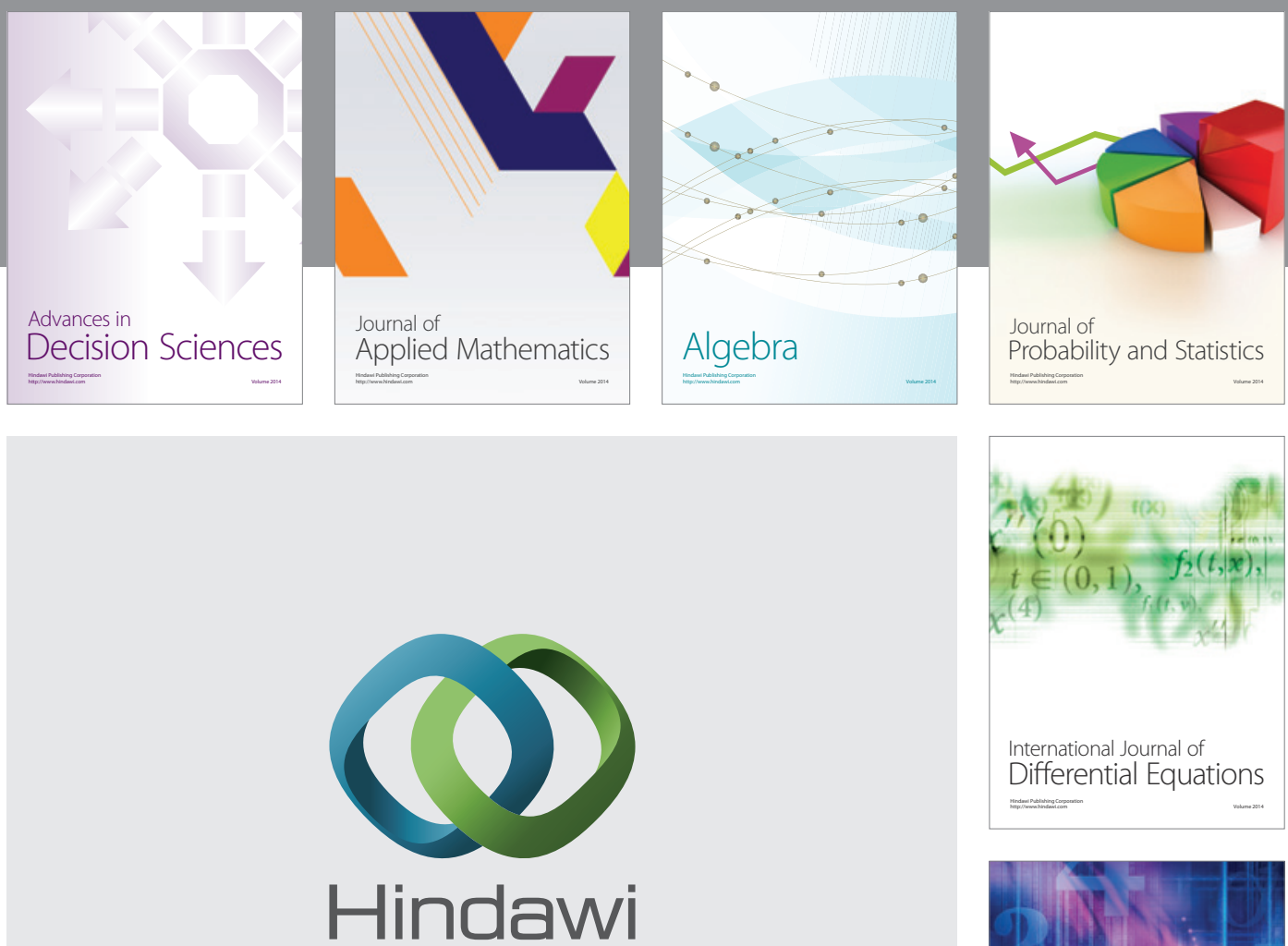

Submit your manuscripts at http://www.hindawi.com
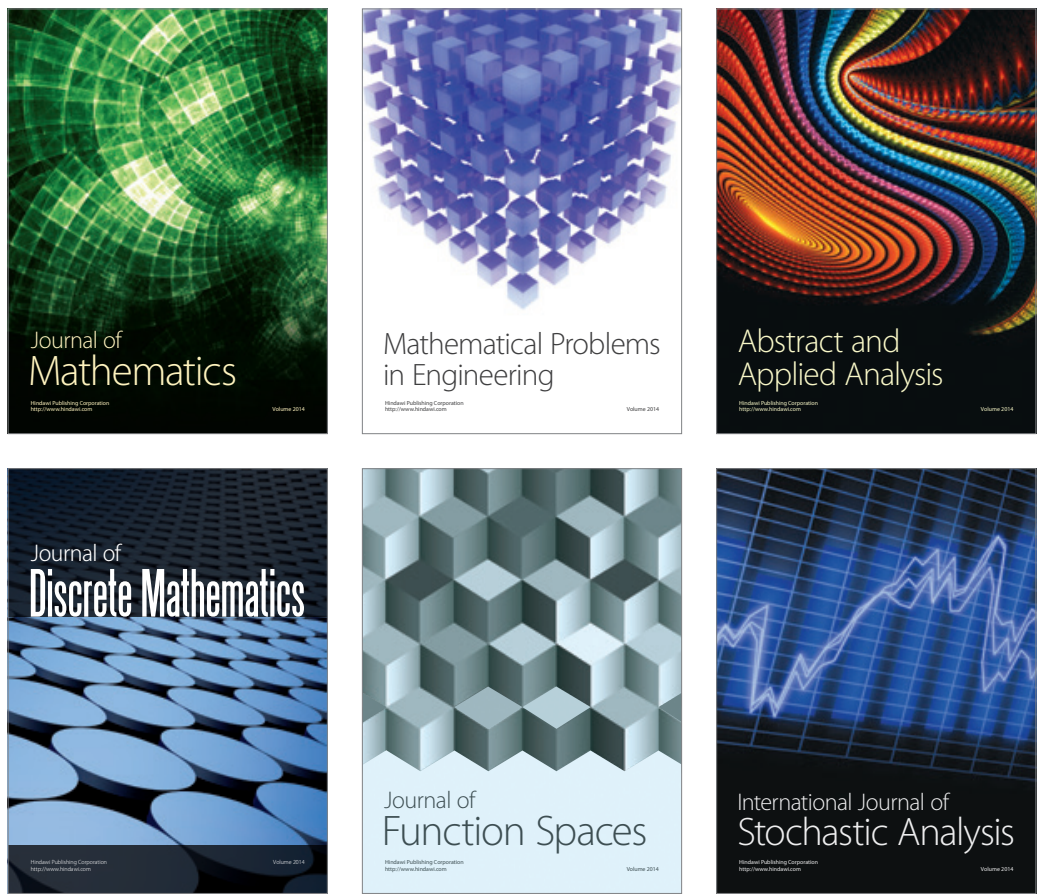

Journal of

Function Spaces

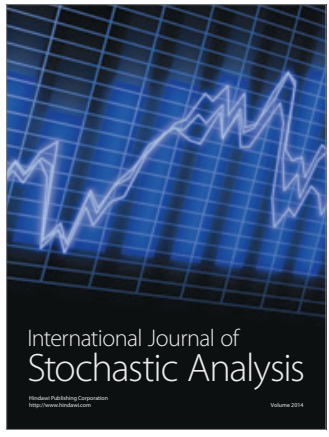

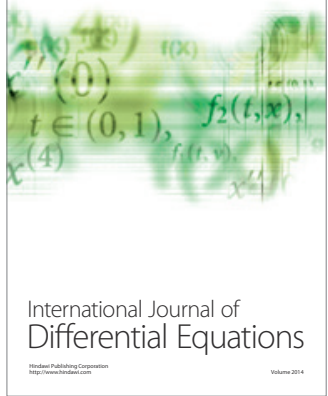
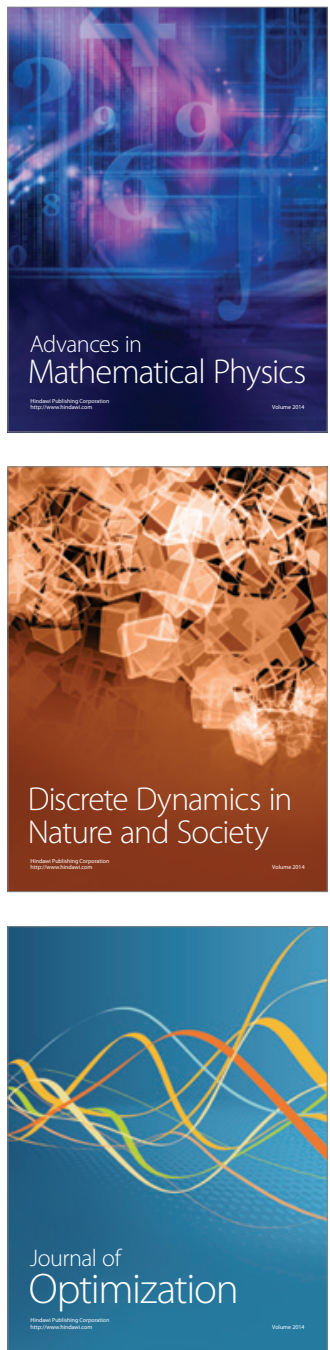